REFERENCES

Douthwaite, A. H. (1954). Lancet, 1, 1345.

Doyle, A. E., and Smirk, F. H (1954). Ibid., 1, 1096

Fowler, P. B. S., and Guz, A. (1954). Brit. Heart J., 16, 6.

Löffler, W. Essellier, A. F., Prött, F., and Wegmann, A. (1953). Schweiz med. W schr., 83, 1012

Vakil, R. J. (1953). J. Indian med. Ass., 23, 97.

Theran

\section{THE TREATMENT OF ESSENTIAL} HYPERTENSION WITH PENTOLINIUM TARTRATE COMBINED WITH RAUWOLFIA ALKALOIDS

BY

C. W. CURTIS BAIN, M.C., D.M., F.R.C.P. Senior Physician, Harrogate General Hospital

F. ASHTON, M.B., Ch.B., B.Sc. Medical Registrar, Harrogate General Hospital AND

\section{B. P. JONES, M.B., Ch.B. General Practitioner}

The autonomic ganglion-blocking agent pentolinium tartrate (pentapyrrolidinium; "ansolysen ") is acknowledged to be an effective agent in the control of hypertension (Smirk, 1953). Difficulties have been experienced in its continued use because of the unpleasant effects of its indiscriminate ganglion-blocking activity-for example, constipation, dry mouth, visual disturbances, etc.-which accompany the hypotensive activity. The rauwolfia alkaloids have been in extensive use in India for a variety of conditions for many years. Vakil (1949) showed that the drug has hypotensive properties. It is a central sedative and also stimulates the smooth musculature of the intestinal tract. The combined use of a rauwolfia alkaloid (reserpine) with pentolinium tartrate was described by Smirk, Doyle, and McQueen (1954). who found that less of the latter was required and that the effect was more sustained. They recommend a method of control by these drugs.

We have used this method, and present a short series of cases in which stabilization had been achieved on pentolinium tartrate alone and which were later restabilized on that drug with the addition of rauwolfia alkaloids ("rauwiloid" $4 \mathrm{mg}$.), taken in a single dose each evening.

All the patients had essential hypertension. Their blood pressure before treatment varied from $300 / 160$ to 240/130. None had evidence of renal involvement. The average dose of pentolinium tartrate when given alone was $840 \mathrm{mg}$. a day. The average daily dose of that drug when combined with rauwolfia alkaloids was 240 mg., a reduction of over two-thirds. One patient who required $440 \mathrm{mg}$. of pentolinium tartrate a day was restabilized on the combination with $60 \mathrm{mg}$. a day.

The corresponding decrease in the undesirable effects of the ganglion-blocking agent was very great, and some patients who had found it impossible to continue with pentolinium tartrate alone are now well stabilized and able to live active lives.

\section{Discussion}

The combined use of pentolinium tartrate and rauwolfia seems to offer a promising treatment of hypertension. In

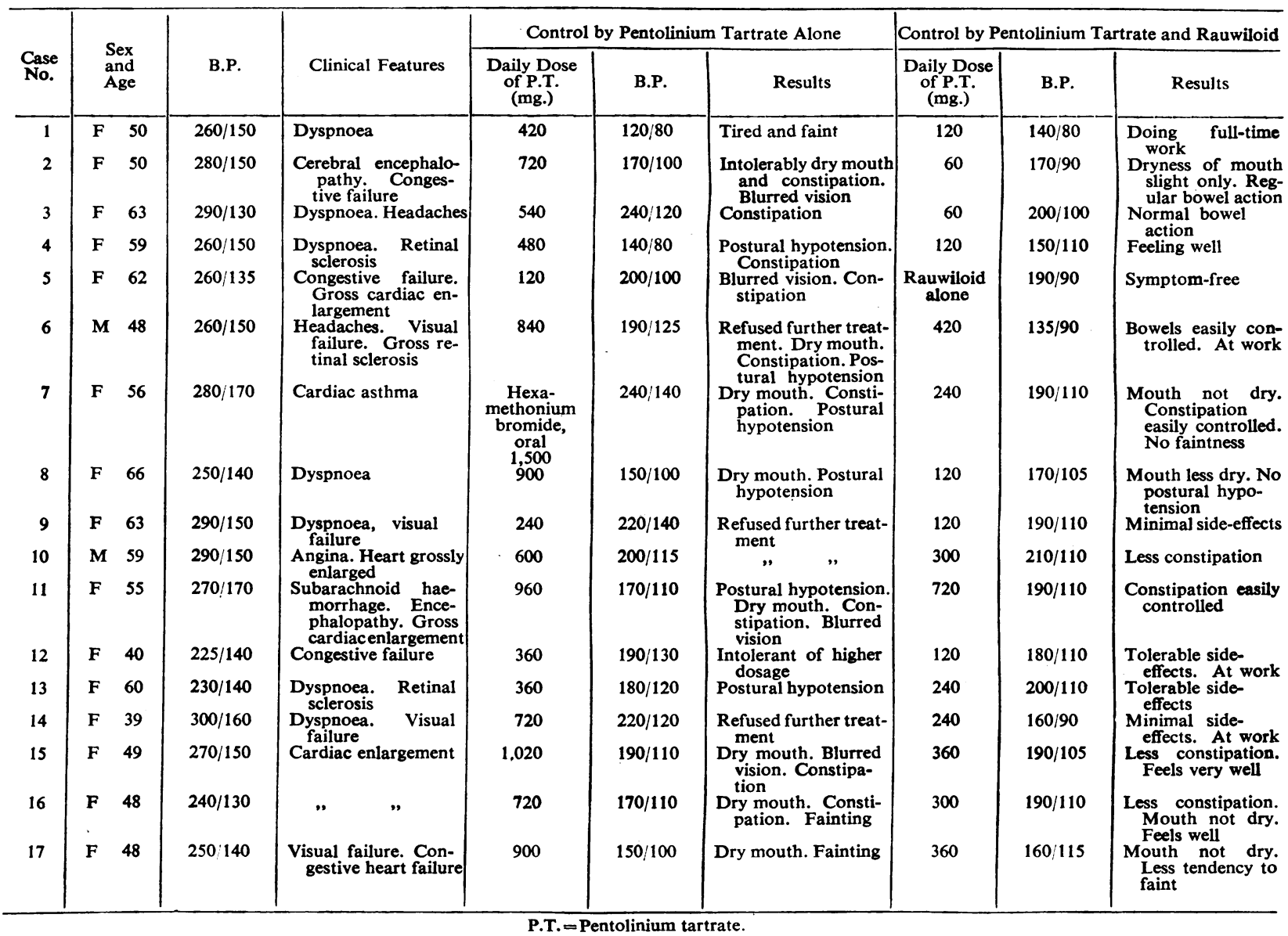


patients who are already stabilized on pentolinium tartrate alone, the dose on adding rauwolfia has usually been reduced to one-third and final adjustments made from that level.

A patient who has had no previous treatment is given rauwolfia for some weeks, as suggested by Smirk et al. (1954). Then pentolinium tartrate is added, starting with 20-mg. doses and increasing by increments of $20 \mathrm{mg}$. until satisfactory levels are obtained. We have found that a better control is achieved when the drug is given three times rather than twice daily.

The reduction in dosage reduces or abolishes the undesirable effects of the ganglionic blockade. Where formerly postural hypotension was a problem, this has been less evident on the combination. Rauwolfia has been shown to stimulate the intestine, and this, in addition to the smaller dose of pentolinium tartrate required, makes the control of the bowels easier. There is therefore less risk of cumulative effect through retention and subsequent absorption of pentolinium tartrate in the bowel.

Patients have been definite in expressing their views that they are much more comfortable, and have been willing to continue treatment, whereas formerly on pentolinium tartrate alone they were incapacitated by weakness, dry mouth, visual disturbances, constipation, and the variability of effect on the degree of hypotension this produced.

In most cases there is no urgency in the control of the hypertension, and gradual reductions of the blood pressure are better tolerated. The aim should be the maximum reduction which keeps the patient comfortable, since the symptoms and signs of hypertension will regress when the pressures have been reduced to levels which are still above the accepted normal.

It would seem also that, once the diagnosis of essential hypertension has been established, cases are better controlled with the patient living his normal life.

\section{Summary}

The use of pentolinium tartrate in combination with rauwoifia alkaloids in the control of essential hypertension is compared with the use of the former drug alone.

The dosage necessary with the combined drugs is greatly reduced.

The undesirable effects of the ganglionic blockade have been much lessened and patients have found the treatment more acceptable.

\section{REFERENCES}

Smirk, F. H. (1953), Lancet, 1, 457.

C. (1954), Ibid., 2, 159 Vakil, R. J. (1949). Brit. Heart J., 11, 350.

The Medical Section of the Library Association held a week-end conference in Birmingham on March 25-28. Members were the guests at dinner of the Vice-chancellor (Professor Robert Aitken), in whose absence Professor H. A. CronNe presided, supported by Professor J. F. D. SHREwsBURY. In a symposium on medical libraries and literature in 1984 the chief topics discussed were the establishment of national editorial assessment boards and a consequent reduction in the number of medical periodicals, academic courses in medical librarianship, changes in the medical profession itself and their effect on library provision, national economic changes and their effects on medical libraries, and the potentialities of new technical methods in documentation. A visit was paid to the Birmingham Medical School, where the sub-dean, Professor C. F. V. SMOut, announced plans for a new medical library building on a scale commensurate with the other splendidly equipped departments. Special exhibitions of rare medical books were on view, both at the School and at the Birmingham Medical Institute.

\section{INEFFECTIVENESS OF CHICKEN ANTI- ULCER FACTORS IN TREATMENT OF GASTRIC AND DUODENAL ULCER IN MAN}

BY

\author{
K. BRØCHNER-MORTENSEN, M.D. \\ N. B. KRARUP, M.D. \\ E. MEULENGRACHT, M.D., LL.D.
}

AND

Aa. VIDEBAK, M.D.

(From the University Hospital of Copenhagen, Medical Department $A$, and from Bispebjerg Hospital Medical Departments $B$ and $C$ )

The present study, carried out in collaboration with Professor H. Dam, is aimed at deciding whether materials acting prophylactically against gizzard ulcer in chicks have any curative effect in gastric and duodenal ulcer in man. Dam (1954) has set out the reason for undertaking this work.

The development and prevention of ulcers in the muscular stomach (gizzard) of the chick have been described by Dam (1934, 1946, 1951), Dam and Schønheyder (1934), Dam and Segal (1945), Dam, Noer, and Søndergaard (1950), Cheney $(1938,1940,1942)$, and others. According to Dam and his associates young chicks reared on an artificial diet containing cod-liver oil develop ulcers which are often severe and may perforate. The disease may be prevented by including in the diet hog liver, calf's brain, or certain extracts therefrom. The prophylactic effect is associated with the lipid fraction as well as with the residue that remains after these organs have undergone extraction with fat solvents. A marked prophylactic effect is obtained by a combination of the lipid extract and an aqueous extract of calf's brain. The aqueous extract contains vitamin $B_{12}$ and may be replaced by this vitamin. In the lipid extract it is the highly unsaturated fraction of the fatty acids that carries protective activity. Arachidonic acid has shown such effect, while fatty acids from fish oils aggravated the symptom.

\section{Material}

We studied 152. patients with gastric or duodenal ulcer. They were admitted to the medical departments $B$ and $C$ of Bispebjerg Hospital and the medical department $A$ of the University Hospital of Copenhagen during the period July 1 to December 1, 1954. Of these patients, 82 were treated with anti-gizzard-ulcer factors and 70 were given placebos. Diagnosis was based on anamnesis, $x$-ray examination (niche deformation), and, if present, demonstrable haemorrhage. All patients showed typical ulcer symptoms.

The patients in the two groups were chosen at random. Each of the three hospital departments was divided into two halves. All patients with gastric or duodenal ulcer admitted to one half formed the experimental group; those with the same diseases admitted to the other half formed the control group. The groups did not differ significantly in sex, age, location of the ulcer, symptoms, or duration of the disease before admission to hospital (Table I).

\section{Treatment}

Patients in the experimental group were given daily for four weeks $80 \mathrm{~g}$. of " preparation A," a granulate consisting of ether extract of calf's brain mixed with three parts of 